\title{
What's the rate of knee osteoarthritis 10 years after anterior cruciate ligament injury? An updated systematic review
}

\author{
Marthe Mehus Lie, ${ }_{1}^{1}$ May Arna Risberg, ${ }^{2,3}$ Kjersti Storheim, ${ }^{1,4}$ Lars Engebretsen, 3,5 \\ Britt Elin Øiestad ${ }^{0} 1$
}

- Additional material is published online only. To view please visit the journal online (http://dx.doi.org/10.1136/ bjsports-2018-099751).

${ }^{1}$ Institute of Physiotherapy, OsloMet - Oslo Metropolitan University, Oslo, Norway 2Department of Sport Medicine, Norwegian School of Sport Sciences, Oslo, Norway ${ }^{3}$ Division of Orthopedic Surgery, Oslo University Hospital, Oslo, Norway

${ }^{4}$ Research and Communication unit for Musculoskeletal Health (FORMI), Oslo University Hospital, Oslo, Norway

${ }^{5}$ Oslo Sports Trauma Research Center, Norwegian School of Sport Sciences, Oslo, Norway

\section{Correspondence to}

Dr Britt Elin Øiestad, Institute of Physiotherapy, OsloMet - Oslo Metropolitan University, Oslo, Norway; brielo@oslomet.no

Accepted 5 March 2019 Published Online First 1 April 2019

\section{Check for updates}

(C) Author(s) (or their employer(s)) 2019. No commercial re-use. See rights and permissions. Published by BMJ.

To cite: Lie MM, Risberg MA, Storheim K, et al. Br J Sports Med 2019:53:1162-1167.

\section{ABSTRACT}

Background This updated systematic review reports data from 2009 on the prevalence, and risk factors, for knee osteoarthritis (OA) more than 10 years after anterior cruciate ligament $(\mathrm{ACL})$ tear.

Methods We systematically searched five databases (PubMed, EMBASE, AMED, Cinahl and SPORTDiscus) for prospective and retrospective studies published after 1 August 2008. Studies were included if they investigated participants with ACL tear (isolated or in combination with medial collateral ligament and/ or meniscal injuries) and reported symptomatic and/or radiographic $O A$ at a minimum of 10 years postinjury. We used a modified version of the Downs and Black checklist for methodological quality assessment and narrative synthesis to report results. The study protocol was registered in PROSPERO.

Results Forty-one studies were included. Low methodological quality was revealed in over half of the studies. At inclusion, age ranged from 23 to 38 years, and at follow-up from 31 to 51 years. Sample sizes ranged from 18 to 780 participants. The reported radiographic $\mathrm{OA}$ prevalence varied between $0 \%$ and $100 \%>10$ years after injury, regardless of follow-up time. The studies with low and high methodological quality reported a prevalence of radiographic $\mathrm{OA}$ between $0 \%-100 \%$ and $1 \%-80 \%$, respectively. One study reported symptomatic knee OA for the tibiofemoral (TF) joint (35\%), and one study reported symptomatic knee OA for the patellofemoral (PF) joint (15\%). Meniscectomy was the only consistent risk factor determined from the data synthesis.

Conclusion Radiographic knee OA varied between $0 \%$ and $100 \%$ in line with our previous systematic review from 2009. Symptomatic and radiographic knee OA was differentiated in two studies only, with a reported symptomatic OA prevalence of $35 \%$ for the TF joint and $15 \%$ for PF joint. Future cohort studies need to include measurement of symptomatic knee OA in this patient group.

PROSPERO registration number CRD42016042693.

\section{INTRODUCTION}

Anterior cruciate ligament (ACL) tears are common injuries ${ }^{1}$ with an annual incidence in the general population of 68.6 per 100000 personyears. $^{2}$ However, the incidence rates among specific sports are reported to be higher (eg, soccer, football, team handball). ${ }^{1}$ The ACL tears occur mostly in young athletes, ${ }^{3}$ and about $50 \%$ of those injured do not return to their preinjury sport activity. ${ }^{4}$ The most important consequence of an ACL tear is development of knee osteoarthritis (OA) at a relatively young age. Post-traumatic OA results in a longer period of joint-related morbidity compared with the non-traumatic OA as developed in elderly, ${ }^{5}$ and reduced quality of life is found in this group. ${ }^{6}$

In 2009 , we published a systematic review on the prevalence and risk factors for radiographic knee OA after ACL tear. ${ }^{7}$ The systematic review included 7 prospective and 24 retrospective cohort studies. In the studies with the best methodological quality, that is, the seven prospective studies, $0 \%-13 \%$ of participants with isolated ACL tears had radiographic OA and $21 \%-48 \%$ of those with additional meniscus injury. Most studies were retrospective, with high quality and low quality (24 of 31 studies). Since this review, additional reviews have investigated different aspects of ACL tear and its consequences. Ajuied et $a l^{8}$ found ACL tear to increase the risk of radiological knee OA [defined with the Kellgren \& Lawrence (K\&L) classification system] by nearly five times. Riccardo et $a l^{9}$ reported mild signs of joint degeneration in 12 included studies of isolated ACL tears. Other studies investigated predictors for tibiofemoral (TF) and patellofemoral (PF) $\mathrm{OA},{ }^{10}$ or compared operative and non-surgical management. ${ }^{11-13}$ The lack of high-quality studies was highlighted, and caution recommended when reviewing the results. No systematic reviews reported the prevalence of symptomatic knee OA. Knee pain is the most important criteria to diagnose $\mathrm{OA},{ }^{14}$ and there is lack of knowledge of symptomatic OA in individuals with ACL tear. We argue that radiographic diagnosed OA alone has limited clinical interest. The aim of this study was to conduct an update of the systematic review from 2009 on the prevalence and risk factors for radiographic knee OA more than 10 years after ACL tear. In addition, we added a summary of the prevalence and risk factors for symptomatic knee OA more than 10 years after ACL tear.

\section{METHODS}

We reported this systematic review according to the Preferred Reporting Items for Systematic Reviews and Meta-Analyses (PRISMA) statement. ${ }^{15}$ This systematic review is an update of a previous systematic review with the same inclusion and exclusion criteria. We included only new data from 1 August 2008 to 1 August 2018 in this study. 
Study selection

The inclusion criteria were: prospective or retrospective cohort study designs, participants with ACL tear treated surgically or non-surgically, isolated ACL tear or ACL tear combined with meniscal and/or medial collateral ligament tear, radiographic assessment as one of the outcomes, a follow-up time of a minimum 10 years, studies published after 1 August 2008, and studies reported in English or Scandinavian languages. The exclusion criteria were: studies on skeletally immature participants, and animal studies. If several cohort studies appeared to be from the same study sample, we included the study that was most relevant according to our research question with emphasis on the prevalence of radiographic and symptomatic OA, and risk factors for OA.

\section{Data sources and searches}

Systematic searches were performed until 1 August 2018 in five different databases by two of the authors (MML and BEØ): PubMed, EMBASE, Cinahl, AMED and SPORTDiscus. A librarian at the Oslo Metropolitan University helped building up the systematic searches. The search strategy for the databases is presented in online supplementary appendix 1. Additionally, we hand searched for relevant published papers in recent systematic reviews, the included studies reference list and other relevant studies.

\section{Data extraction}

Two authors (MML and BEØ) extracted the study characteristics, including: type of study, number of participants at start and follow-up, age, sex, type of treatment, concomitant injuries, reinjuries, the knee compartment investigated, the prevalence of symptomatic and radiographic OA, the radiological classification system used, and the radiological method. In cases where studies reported raw data for the radiographic outcome, we based the extracted data on the specified radiological classifications systems' cut-off values. Reported risk factors were extracted from all studies that used regression analysis.

\section{Study methodological quality assessment}

Four of the authors (MML, LE, KS and MAR) independently assessed the study quality according to guidelines from the Centre of Reviews and Dissemination, ${ }^{16}$ and questions from the Downs and Black checklist. ${ }^{17}$ The checklist was modified and operationalised for the purpose of this systematic review. Each component of study quality was rated with YES (1 point), NO $(0$ points) or UNCLEAR ( 0 points). Studies with a score $\geq 8$ (>60\% of the maximal attainable score) were classified as high quality according to another systematic review from our group. ${ }^{18}$ Two authors scored the studies independently, and then the scores were compared (MML and LE; MML and KS; MML and MAR). In cases of disagreement, the authors tried to achieve consensus. If consensus was not reached, a third author (BEØ) gave a final judgement.

\section{Data synthesis}

The large heterogeneity in the reporting of outcomes in the included studies precluded meta-analysis. We used narrative synthesis to investigate and report similarities, differences and results between the included studies. ${ }^{19} 20$ The results from this update were discussed against the results from the systematic review from 2009.

\section{RESULTS}

\section{Identification and selection of the literature}

The systematic searches identified 1853 new studies from 1 August 2008. After removing duplicates, 1712 studies were screened by title and/or abstract. A total of 57 studies were considered as eligible and were read in full-text. Of these, 16 studies were excluded, as they did not fulfil our inclusion and/ or exclusion criteria. Finally, 41 studies were included in this systematic review (figure 1 ). Of these, 23 had a prospective study design, ${ }^{21-42}$ and 18 had a retrospective study design. ${ }^{43-60}$

\section{Excluded studies}

We were not able to extract the OA prevalence from five studies. ${ }^{58}$ 61-64 The respective authors were contacted by mail in an attempt to receive the data, and one author responded. ${ }^{58}$ The systematic searches identified 16 studies using data from the same cohort. ${ }^{2728323641425465-73}$ We excluded eight of these ${ }^{66-73}$ to avoid reporting OA prevalence from the same cohort. In the study by Holm et $a l^{42}$ we only extracted the PF OA prevalence as the TF OA prevalence data was reported in the study by Øiestad et al. ${ }^{27}$

\section{Description of the included studies}

The characteristics of the included studies are presented in online supplementary table 1 . A total of 4919 participants were included, and sample sizes ranged from 18 to 780 participants. The male and female sample sizes varied from 7 to 106 and 0 to 109 , respectively. Age at inclusion ranged from 23 to 38 years $(28.1 \pm 3)$, and age at follow-up ranged from 31 to $51(42.2 \pm 5)$ years. A total of 4709 participants (96\%) were treated surgically, and $210(4 \%)$ were treated non-surgically. Thirty-five studies evaluated surgically treated participants only, ${ }^{21-30} 32343538-4648-5355-6065$ and six studies evaluated both surgically and non-surgically treated participants. $^{31} 3336374754$ Twelve studies $2127283739404245-4853$ reported OA results for the contralateral knee, involving 833 knees. Eighteen studies used bone-patellar-tendon-bone (BPTB) graft, ${ }^{23} 28-3032$ 36-38 42-44 4748515354565712 used hamstring tendon (HT) graft, 222425333941464950525860 seven studies included both BPTB and HT graft, ${ }^{21} 262735455965$ two studies used synthetic graft, $^{3455}$ and one study used HT and synthetic graft. ${ }^{40}$ One study did not report the type of graft. ${ }^{31}$ The follow-up time ranged from 10 to 24 years, with a mean follow-up time of 13.7 years.

\section{Methodological quality}

Online supplementary table 2 shows the methodological quality assessments. The lowest score achieved was 3, and the highest was 11 . Nineteen studies (46\%) achieved a score $\geq 8$ and were considered to have high quality. The prospective studies achieved a mean score of 7.8 with a highest score of 11 and a lowest score of 3 . The retrospective studies achieved a mean score of 6.7 with a highest score of 11 and a lowest score of 3 . In 3.6\% of the questions the authors could not reach consensus regarding the score, and the third author (BEØ) gave final judgement. Twenty-seven studies $^{21-2331-3739-4144-46484951-5557586065}$ did not fulfil the criteria for confounding factors, 30 studies $^{21-2325-2729-36384042454850-586065}$ did not fulfil the criteria of appropriate sample size calculation and drop-out rates, and 22 studies $^{23} 25293034-3638434449-596573$ did not fulfil the criteria for description of qualified radiologist

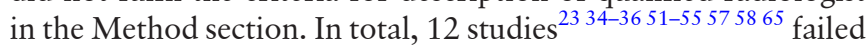
to report both confounding factors, sample size calculation and drop-out rate, and had no information on qualified radiologist was included in the outcome assessment. 


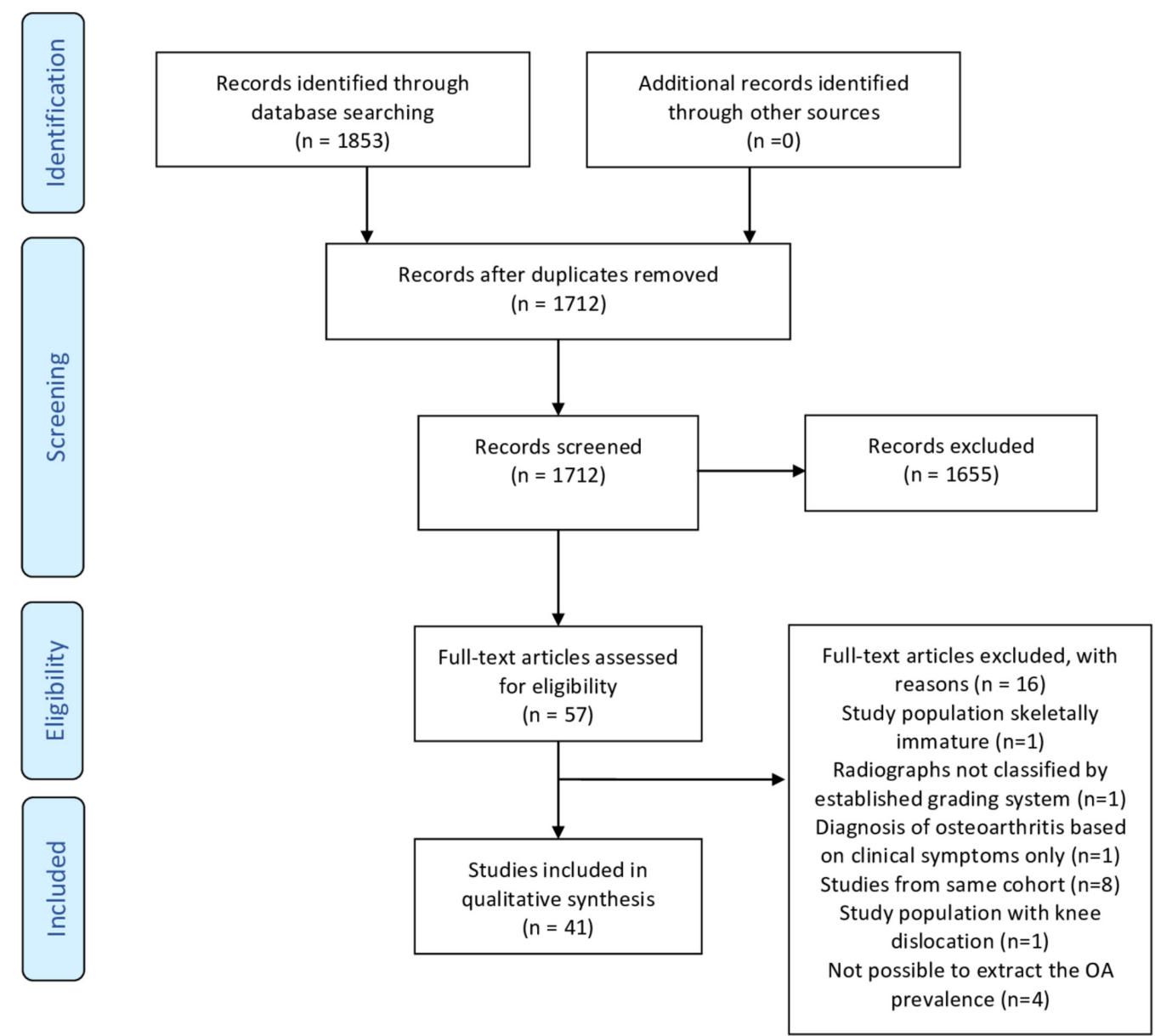

Figure 1 Flow diagram. OA, osteoarthritis.

\section{Prevalence of radiographic $\mathrm{OA}$}

The prevalence of radiographic OA in the TF joint ranged from $0 \%$ to $100 \%$ (online supplementary table 3 ). The retrospective and prospective studies reported a prevalence of radiographic knee OA between $0 \%-79 \%$ and $0 \%-100 \%$, respectively. The high-quality and low-quality studies reported a prevalence of radiographic knee OA between 1\%-80\% and $0 \%-100 \%$, respectively. Fourteen of the included studies 2223252831323638394243495960 reported radiographic OA prevalence for the PF joint, ranging from $0 \%$ to $41 \%$. Of these, one study ${ }^{28}$ reported and investigated the prevalence of radiographic OA in the PF joint solely (26\%). Six studies ${ }^{31} 3336374754$ reported OA prevalence for surgically and non-surgically treated participants, which varied from $23 \%$ to $80 \%$ and $8 \%$ to $68 \%$, respectively. Participants treated with BPTB graft had OA prevalence varying between $2 \%$ and $80 \%$, and participants treated with HT graft had OA prevalence varying between $0 \%$ and $73 \%$. Three studies ${ }^{34} 4055$ investigated OA prevalence in participants treated with synthetic graft, showing an OA prevalence of $39 \%, 50 \%$ and $100 \%$. Figure 2 illustrates the radiographic OA prevalence for the range of follow-up time.

Eleven of the included studies $21272837394045-4853$ reported radiographic $\mathrm{OA}$ prevalence in the contralateral knee, ranging from $2 \%$ to $38 \%$. Of these, five studies reported results from uninjured contralateral knees, ${ }^{2728454853}$ four studies 21394042 reported additional injuries to the contralateral knee (ACL injury, chondral lesion, meniscal injury, medial collateral ligament and lateral collateral ligament injury), while three studies ${ }^{37} 4647$ did not provide any information regarding additional injuries to the contralateral knee.

\section{Prevalence of symptomatic $O A$}

Two studies evaluated the prevalence of symptomatic knee OA. ${ }^{27} 28$ Of these, one study ${ }^{27}$ reported a $35 \%$ symptomatic OA prevalence for the TF joint, and one ${ }^{28}$ study reported a $15 \%$ symptomatic OA prevalence for the PF joint (figure 3).

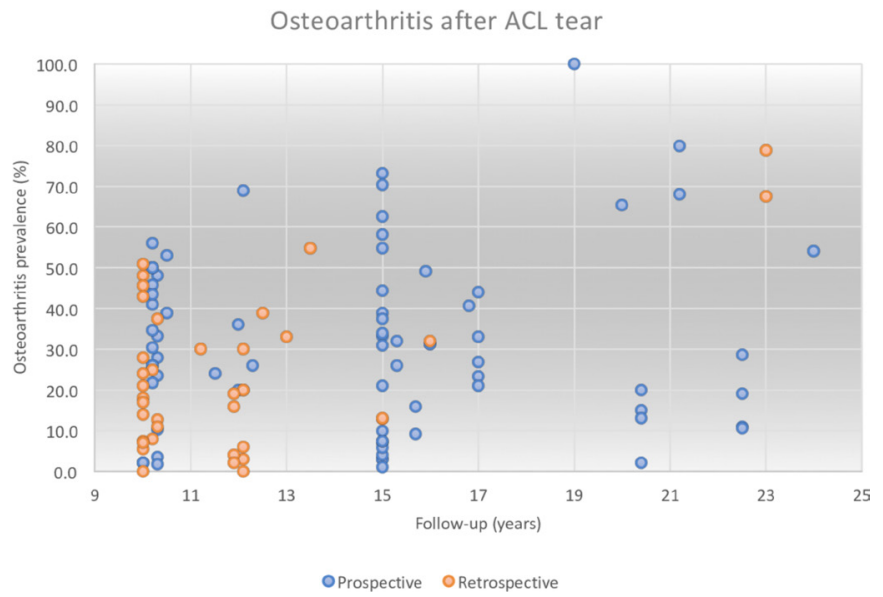

Figure 2 Illustration of radiographic osteoarthritis prevalence. $\mathrm{ACL}$, anterior cruciate ligament. 


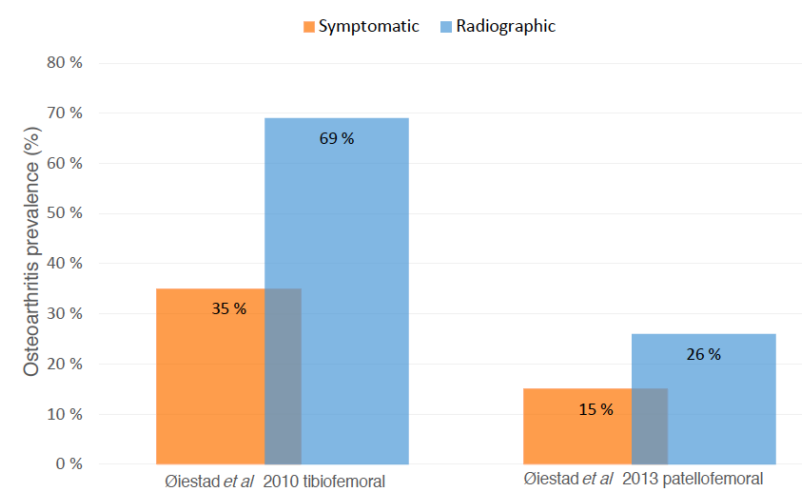

Figure 3 Comparison of symptomatic and radiographic knee osteoarthritis.

\section{Risk factors for the development of knee $\mathrm{OA}$}

A total of 26 studies reported risk factors, and all but one study $^{23}$ used statistical analysis for identification of risk factors. Twelve studies investigated risk factors by regression analysis, ${ }^{22} 2426-303238435059$ and three reported adjustment for confounding variables. ${ }^{27} 2830$ Of these three, two ${ }^{27} 30$ studies reported risk factors for radiographic knee OA, one study ${ }^{27}$ investigated risk factors for symptomatic knee $\mathrm{OA}$ and one study ${ }^{28}$ investigated risk factors for PF OA.

\section{Risk factors for radiographic $O A$}

The reported risk factors for radiographic TF OA were increased age at surgery, additional injury, range of motion loss at final follow-up, partial medial meniscectomy and articular cartilage damage. For PF OA, the reported risk factors were increased age, TF OA, impaired knee function, more symptoms, pain during activity and kneeling pain.

The variables reported as non-significant risk factors for TF OA were quadriceps muscle weakness measured in absolute values (joules) or absolute values normalised to bodyweight (\%BW), functional tests and removal of lateral meniscus. For PF OA the variables reported as non-significant were knee laxity, self-reported knee function, quadriceps strength and hop test up to 2 years postoperatively.

\section{Risk factors for symptomatic $\mathrm{OA}$}

The reported risk factors for symptomatic knee OA were impaired self-reported knee function 2 years postoperatively and loss of quadriceps strength between 2 and 10-15 years. Non-significant risk factors for symptomatic knee OA were quadriceps muscle weakness measured in absolute values (joules) or absolute values normalised to bodyweight (\%BW) and functional tests. Online supplementary appendix 2 shows the results for the reported risk factors for all 12 studies using regression analysis.

\section{DISCUSSION}

This updated systematic review found that knee OA prevalence varied from $0 \%$ to $100 \%$. We identified 41 new studies from 2008 investigating 4919 individuals with ACL tear with a mean follow-up time of 13.7 years. Low methodological quality was revealed among more than half of the studies. In the present review we also investigated the prevalence of symptomatic knee OA, and found it to be $35 \%$ for the TF joint and $15 \%$ for the PF joint.
The reported prevalence of radiographic OA varied between $0 \%$ and $100 \%$, regardless of follow-up time as shown in figure 2, which is consistent with the reported prevalence from the previous systematic review from 2009. In three of the 41 studies, the participants had isolated ACL injury at study start, but at follow-up all 41 studies reported additional injuries. Importantly, the majority of the studies did not concretise how many of the participants who had an additional injury or not, and none of the included studies reported radiographic and/or symptomatic OA prevalence only for participants with isolated ACL tears at follow-up. In the review from 2009, eight studies reported OA prevalence for knees with isolated ACL tear with a prevalence varying between $0 \%$ and $13 \%$, contrary to $21 \%-48 \%$ in combined ACL injuries. ${ }^{7}$ The lower OA prevalence reported in isolated ACL tears indicates that the additional injuries occurring at the time of ACL tear, and/or subsequently may be an important contributor to OA development, ${ }^{74}$ as is also supported by others. ${ }^{9}$

Radiographic OA was described in $2 \%-38 \%$ of contralateral knees (from 12 studies). This indicates a higher OA prevalence in the contralateral knee compared with the global age-standardised prevalence, which is reported to be $3.8 \% .^{75}$ An ACL tear may cause bilateral movement responses, leading to proprioceptive deficits in the healthy knee from the ACL injured knee. ${ }^{76-78}$ Such adaptations may predispose the contralateral knee to overuse and result in premature OA development, compared with the general population. As knee $\mathrm{OA}$ is a complex interaction affected by multiple factors, one cannot rule out the possibility that heavy physical work, kneeling, crawling, repetitive movements and/or genetics ${ }^{79} 80$ have contributed to the higher occurrence of $\mathrm{OA}$ in the contralateral knee as seen in this systematic review.

$\mathrm{PF}$ radiographic OA prevalence ranged between $0 \%$ and $41 \%$. Hart $e t a l^{81}$ reported structural damage from MRIs of the PF joint, with a prevalence of $29 \%$ in ACL injured or reconstructed participants. Although K\&L, The International Knee Documentation Committee (IKDC) and The Osteoarthritis Research Society International (OARSI) are commonly used to quantify the severity of PF OA, neither of these radiological classification systems have validated definitions of the PF joint, which likely may explain some of the variation in the results. ${ }^{81} 82$ More studies are needed to evaluate the different radiological classification systems ability to detect degenerative changes in the PF joint to get a better understanding of PF OA.

OA prevalence $>10$ years post-ACL tear was not different in those treated surgically (8\%-68\%) compared with non-surgically $(24 \%-80 \%)$, which indicates little difference in OA development between treatment options. The findings are in line with a randomised controlled trial study by Frobell et $a l^{83}$ who reported no difference between surgically and non-surgically treated participants at 5 -year follow-up. This is confirmed by recent systematic reviews and meta-analyses, but no RCT studies were included in these reviews. ${ }^{11-13}$ Studies have shown that ACL reconstruction is not a prophylactic treatment in the development of $\mathrm{OA},{ }^{8485}$ which may explain the small differences between treatment options. Similarly, no new knowledge about the influence of graft type can be extracted from this review, also in line with findings from other studies. ${ }^{86-88}$

Symptomatic knee OA prevalence was reported in two included studies only. One study ${ }^{27}$ investigated the TF joint, and one study ${ }^{28}$ investigated the PF joint with a reported prevalence of $35 \%$ and $15 \%$, respectively. In these two studies, approximately half of those who were diagnosed with radiographic knee OA had symptomatic knee OA. A number of authors have highlighted the poor correlation between radiologically determined 
OA and pain, ${ }^{89-93}$ but very few studies have investigated the prevalence of symptomatic knee OA following ACL tear. Suter et $a l^{94}$ estimated that the lifetime risk of symptomatic knee OA after ACL and meniscal tears was 34\%, which is similar to our findings for the TF joint. Also, Lohmander et al ${ }^{95}$ reported $42 \%$ symptomatic radiographic knee OA in female soccer players 12 years after ACL tear, comparable to the other studies of symptomatic knee OA after ACL tear. Jones et a $l^{96}$ compared participants with early and advanced structural changes in the TF joint. Their results showed that the severity of the reported pain was similar between the groups, suggesting that the degree of radiological changes does not correspond with the severity of pain. The reason for the weak correlation between radiographic findings and pain is still not fully understood. ${ }^{92} 9397$

\section{Risk factors for development of knee OA}

Twelve of the included studies performed a thorough analysis of risk factors for OA. Nine of these did not report if they had taken confounding variables into consideration, which reduces confidence in the results. Similar findings were reported in a systematic review by van Meer et $a l^{10}$ who highlighted the absence of suitable analytical approaches. A consequence of insufficiently planned studies is that the risk factors investigated are due to chance. Not adjusting for confounding variables can lead to false-positive results, as the reported findings may be a result of other underlying factors.

In total, three of the included studies did a multivariate regression analysis adjusting for confounding variables. Meniscectomy was the only consistent risk factor for radiographic OA across several studies. Meniscus injury, often treated by meniscectomy, is the most investigated and documented risk factor, and it occurs in approximately $75 \%$ of participants with ACL injury. ${ }^{98}$ The menisci provide stability in the TF joint, distributes load, absorbs shock, lubricates the knee joint and protect the articular cartilage from excessive axial loading. ${ }^{99} 100$ When damaged, the axial loading on the articular cartilage increases, which predispose and increased the risk of OA development. ${ }^{9}{ }^{100}$ Studies have shown a strong correlation between meniscal lesions, cartilage loss and subchondral bone marrow lesions which are important factors in OA development. ${ }^{101}$ In the present review, meniscal injuries were commonly reported at initial ACL injury or during follow-up period, which may explain the increased OA prevalence that we report compared with isolated ACL injuries. ${ }^{9}$

In addition to meniscectomy, increased age at surgery, range of motion loss at final follow-up and articular cartilage damage were reported as risk factors for radiographic knee OA. Two of the included studies reported that quadriceps muscle weakness was not a significant risk factor for knee OA development, ${ }^{27} 28$ but prior systematic reviews have provided conflicting conclusions regarding this association. ${ }^{18} 102$ The reported risk factors are in line with other findings, ${ }^{10} 103$ but do not add new insight or increase the understanding of the development of OA. We suggest that multivariate regression analysis should be used in future multicentre prospective cohort studies with frequent follow-ups to investigate risk factors for development of symptomatic knee OA, ${ }^{104}$ and studies need to differentiate between radiographic and symptomatic OA to thoroughly explore this association.

\section{Methodological quality assessment}

Overall, the 41 included studies mean methodological quality assessment score was 7.2 out of 12 (range 3-11). Our review revealed small differences in the reported OA prevalence between the high-quality and low-quality studies. This does not correspond with the findings from the 2009 review, ${ }^{7}$ where the high-quality studies reported lower OA prevalence. It should be noted that we used different checklists and therefore the results cannot be directly compared. Unlike the 2009 review, we did not distinguish between study design in the quality assessment, which may explain the small difference between the prospective and retrospective studies.

In the literature there is no consensus regarding high or low methodological quality, and evaluating studies from this perspective can be problematic. ${ }^{16}$ We chose to distinguish between high and low quality in line with another similar article, with a cut-off score of $\geq 60 \%$, which in this case was a score of $\geq 8 .{ }^{18}$ The results are only valid for this systematic review, and should not be directly transferred to other contexts, or interpreted as the truth.

A weakness of our quality assessment was that we did not distinguish between the impact of particular questions. Lack of fulfilling the criteria for question number 5, 7, 9 and 12 may be of greater concern for the methodological quality as these questions investigates the reporting of confounding variables, the power of the study, validity and reliability of the outcome measures, and the reliability of the radiographic readers. Many of our results did not fulfil these criteria. Consequently, the reported results from these studies have potentially a lower quality and should be considered with caution.

\section{Limitations}

This systematic review has some limitations. The studies were heterogeneous, which precluded a meta-analysis. We only included studies written in English or Scandinavian languages. Not all studies had a main purpose to evaluate the OA prevalence. The methodological quality assessment has no gold standard and should be carefully interpreted. We attempted to retrieve missing OA data, but only establish contact with the authors of one study. There is no consensus of how to define symptomatic knee OA in the literature, and the two studies in this review defined symptomatic OA as $K \& L$ pain on most days the last month before the assessment. Two of the included studies used the highest cut-off from the radiographic scoring system to define symptomatic knee OA. We chose not to report these findings, as one cannot assume that those with the worse radiological grading automatically corresponds with pain and symptoms. Finally, we did not include data from our study from 2009 in this update because we reported the results descriptively, and merging the studies would not change our descriptive results.

\section{CONCLUSION}

At a minimum of 10 years following an ACL tear the reported prevalence of radiographic knee OA varied between $0 \%$

\section{What is already known}

The prevalence of knee osteoarthritis (OA) in individuals with anterior cruciate ligament $(\mathrm{ACL})$ injury varies between $0 \%$ and $13 \%$ for isolated injuries and between $21 \%$ and $43 \%$ for combined $\mathrm{ACL}$ and meniscal injuries more than 10 years after the injury.

- Meniscectomy is the most important risk factor for development of knee OA after ACL injury. 


\section{What are the new findings}

- Very few studies have differentiated between symptomatic and radiographic knee $\mathrm{OA}$ in $\mathrm{ACL}$ injured individuals.

- The prevalence of symptomatic knee OA was 35\% for the tibiofemoral joint and $15 \%$ for the patellofemoral joint more than 10 years after $A C L$ injury.

- The reported prevalence of radiographic knee OA varies between $0 \%$ and $100 \%$ regardless of follow-up time.

- There is still an insufficient number of high-quality studies clearly reporting prevalence of knee $\mathrm{OA}$ after $\mathrm{ACL}$ injury.

and $100 \%$. Two studies investigated symptomatic knee OA, showing a prevalence of $35 \%$ for the TF joint and $15 \%$ for the PF joint. Meniscectomy is a significant risk factor for OA development. No firm conclusion can be drawn from non-significant risk factors based on our results. More highquality studies are required to detect the true prevalence of knee OA following ACL injuries. There is a strong need for studies differentiating symptomatic and radiographic knee OA. Symptomatic knee OA has high clinical relevance, and is the reason why people seek healthcare.

Contributors All coauthors have read, commented and reviewed at least two versions of the manuscript and the final draft. All coauthors have been involved in the quality assessments of the articles included in the systematic review. All coauthors agreed to update the systematic review with this design and the new added research question on symptomatic knee OA. MML and BEØ performed the systematic searches and selected articles for inclusion.

Funding The authors have not declared a specific grant for this research from any funding agency in the public, commercial or not-for-profit sectors.

Competing interests None declared.

Patient consent for publication Not required.

Provenance and peer review Not commissioned; externally peer reviewed.

\section{REFERENCES}

1 Moses B, Orchard J, Orchard J. Systematic review: Annual incidence of ACL injury and surgery in various populations. Res Sports Med 2012;20(3-4):157-79.

2 Sanders TL, Maradit Kremers H, Bryan AJ, et al. Incidence of Anterior Cruciate Ligament Tears and Reconstruction. Am J Sports Med 2016;44:1502-7.

3 Ytterstad K, Granan L-P, Ytterstad B, et al. Registration rate in the Norwegian Cruciate Ligament Register. Acta Orthop 2012;83:174-8.

4 Ardern CL, Webster KE, Taylor NF, et al. Return to sport following anterior cruciate ligament reconstruction surgery: a systematic review and meta-analysis of the state of play. Br I Sports Med 2011;45:596-606.

5 Stiebel M, Miller LE, Block JE. Post-traumatic knee osteoarthritis in the young patient: therapeutic dilemmas and emerging technologies. Open Access I Sports Med 2014;5:73-9.

6 Filbay SR, Ackerman IN, Dhupelia S, et al. Quality of Life in Symptomatic Individuals After Anterior Cruciate Ligament Reconstruction, With and Without Radiographic Knee Osteoarthritis. J Orthop Sports Phys Ther 2018;48:398-408.

7 Øiestad BE, Engebretsen L, Storheim K, et al. Knee osteoarthritis after anterior cruciate ligament injury: a systematic review. Am I Sports Med 2009;37:1434-43.

8 Ajuied A, Wong F, Smith C, et al. Anterior cruciate ligament injury and radiologic progression of knee osteoarthritis: a systematic review and meta-analysis. Am J Sports Med 2014;42:2242-52.

9 Riccardo C, Fabio C, Pietro R. Knee Osteoarthritis after Reconstruction of Isolated Anterior Cruciate Ligament Injuries: A Systematic Literature Review. Joints 2017;5:39-43.

10 van Meer BL, Meuffels DE, van Eijsden WA, et al. Which determinants predict tibiofemoral and patellofemoral osteoarthritis after anterior cruciate ligament injury? A systematic review. Br J Sports Med 2015;49:975-83.

11 Chalmers PN, Mall NA, Moric M, et al. Does ACL reconstruction alter natural history?: A systematic literature review of long-term outcomes. J Bone Joint Surg Am 2014:96:292-300

12 Smith TO, Postle K, Penny F, et al. Is reconstruction the best management strategy for anterior cruciate ligament rupture? A systematic review and meta-analysis comparing anterior cruciate ligament reconstruction versus non-operative treatment. Knee 2014;21:462-70.
13 Harris KP, Driban JB, Sitler MR, et al. Tibiofemoral Osteoarthritis After Surgical or Nonsurgical Treatment of Anterior Cruciate Ligament Rupture: A Systematic Review. J Athl Train 2017;52:507-17.

14 Altman R, Asch E, Bloch D, et al. Development of criteria for the classification and reporting of osteoarthritis. Classification of osteoarthritis of the knee. Diagnostic and Therapeutic Criteria Committee of the American Rheumatism Association. Arthritis Rheum 1986;29:1039-49.

15 Moher D, Liberati A, Tetzlaff J, et al. Preferred reporting items for systematic reviews and meta-analyses: the PRISMA statement. Ann Intern Med 2009;151:264.

16 Centre for Reviews and Dissemination. Systematic reviews. CRD' Guidance for undertaking reviews in health care: York Publishing Services Ltd, 2009. https://www. york.ac.uk/media/crd/Systematic_Reviews.pdf.

17 Downs SH, Black N. The feasibility of creating a checklist for the assessment of the methodological quality both of randomised and non-randomised studies of health care interventions. J Epidemiol Community Health 1998:52:377-84.

18 Culvenor AG, Ruhdorfer A, Juhl C, et al. Knee Extensor Strength and Risk of Structural, Symptomatic, and Functional Decline in Knee Osteoarthritis: A Systematic Review and Meta-Analysis. Arthritis Care Res 2017;69:649-58.

19 Munn Z, Tufanaru C, Aromataris E. JBI's systematic reviews: data extraction and synthesis. Am J Nurs 2014;114:49.

20 Snilstveit B, Oliver S, Vojtkova M. Narrative approaches to systematic review and synthesis of evidence for international development policy and practice. J Dev Effect 2012:4:409-29.

21 Björnsson H, Samuelsson K, Sundemo D, et al. A Randomized Controlled Trial With Mean 16-Year Follow-up Comparing Hamstring and Patellar Tendon Autografts in Anterior Cruciate Ligament Reconstruction. Am J Sports Med 2016:44:2304-13.

22 Bourke HE, Gordon DJ, Salmon L, et al. The outcome at 15 years of endoscopic anterior cruciate ligament reconstruction using hamstring tendon autograft for 'isolated' anterior cruciate ligament rupture. J Bone Joint Surg Br 2012;94-B:630-7.

23 Felmet $\mathrm{G}$. Implant-free press-fit fixation for bone-patellar tendon-bone $\mathrm{ACL}$ reconstruction: 10-year results. Arch Orthop Trauma Surg 2010;130:985-92.

24 Janssen RP, du Mée AW, van Valkenburg J, et al. Anterior cruciate ligament reconstruction with 4-strand hamstring autograft and accelerated rehabilitation: a 10-year prospective study on clinical results, knee osteoarthritis and its predictors. Knee Surg Sports Traumatol Arthrosc 2013;21:1977-88.

25 Johnson VL, Roe JP, Salmon LJ, et al. Does Age Influence the Risk of Incident Knee Osteoarthritis After a Traumatic Anterior Cruciate Ligament Injury? Am I Sports Med 2016;44:2399-405.

26 Leys T, Salmon L, Waller A, et al. Clinical results and risk factors for reinjury 15 years after anterior cruciate ligament reconstruction: a prospective study of hamstring and patellar tendon grafts. Am J Sports Med 2012;40:595-605.

27 Øiestad BE, Holm I, Gunderson R, et al. Quadriceps muscle weakness after anterior cruciate ligament reconstruction: a risk factor for knee osteoarthritis? Arthritis Care Res 2010;62:1706-14

28 Øiestad BE, Holm I, Engebretsen L, et al. The prevalence of patellofemoral osteoarthritis 12 years after anterior cruciate ligament reconstruction. Knee Surgery, Sports Traumatology, Arthroscopy 2013;21:942-9.

29 Pernin J, Verdonk P, Si Selmi TA, et al. Long-term follow-up of 24.5 years after intra-articular anterior cruciate ligament reconstruction with lateral extra-articular augmentation. Am I Sports Med 2010;38:1094-102.

30 Shelbourne KD, Urch SE, Gray T, et al. Loss of normal knee motion after anterior cruciate ligament reconstruction is associated with radiographic arthritic changes after surgery. Am J Sports Med 2012;40:108-13.

31 Swärd P, Fridén T, Boegård T, et al. Association between varus alignment and posttraumatic osteoarthritis after anterior cruciate ligament injury. Knee Surg Sports Traumatol Arthrosc 2013;21:2040-7.

32 Thompson SM, Salmon LJ, Waller A, et al. Twenty-Year Outcome of a Longitudinal Prospective Evaluation of Isolated Endoscopic Anterior Cruciate Ligament Reconstruction With Patellar Tendon or Hamstring Autograft. Am I Sports Med 2016;44:3083-94.

33 Tsoukas D, Fotopoulos V, Basdekis $G$, et al. No difference in osteoarthritis after surgical and non-surgical treatment of ACL-injured knees after 10 years. Knee Surg Sports Traumatol Arthrosc 2016:24:2953-9.

34 Ventura A, Terzaghi C, Legnani C, et al. Synthetic grafts for anterior cruciate ligament rupture: 19-year outcome study. Knee 2010;17:108-13.

35 Webster KE, Feller JA, Hartnett $\mathrm{N}$, et al. Comparison of Patellar Tendon and Hamstring Tendon Anterior Cruciate Ligament Reconstruction: A 15-Year Follow-up of a Randomized Controlled Trial. Am J Sports Med 2016;44:83-90.

36 Neuman P, Kostogiannis I, Fridén T, et al. Patellofemoral osteoarthritis 15 years after anterior cruciate ligament injury--a prospective cohort study. Osteoarthritis Cartilage 2009;17:284-90

37 van Yperen DT, Reijman M, van Es EM, et al. Twenty-Year Follow-up Study Comparing Operative Versus Nonoperative Treatment of Anterior Cruciate Ligament Ruptures in High-Level Athletes. Am I Sports Med 2018;46:1129-36.

38 Shelbourne KD, Benner RW, Gray T. Results of Anterior Cruciate Ligament Reconstruction With Patellar Tendon Autografts: Objective Factors Associated With the Development of Osteoarthritis at 20 to 33 Years After Surgery. Am J Sports Med 2017:45:2730-8 
39 Järvelä S, Kiekara T, Suomalainen P, et al. Double-Bundle Versus Single-Bundle Anterior Cruciate Ligament Reconstruction: A Prospective Randomized Study With 10-Year Results. Am J Sports Med 2017;45:2578-85.

40 Chen T, Zhang P, Chen J, et al. Long-Term Outcomes of Anterior Cruciate Ligament Reconstruction Using Either Synthetics With Remnant Preservation or Hamstring Autografts: A 10-Year Longitudinal Study. Am J Sports Med 2017;45:2739-50.

41 Zaffagnini S, Marcheggiani Muccioli GM, Grassi A, et al. Over-the-top ACL Reconstruction Plus Extra-articular Lateral Tenodesis With Hamstring Tendon Grafts: Prospective Evaluation With 20-Year Minimum Follow-up. Am J Sports Med 2017:45:3233-42.

42 Holm I, Oiestad BE, Risberg MA, et al. No differences in prevalence of osteoarthritis or function after open versus endoscopic technique for anterior cruciate ligament reconstruction: 12-year follow-up report of a randomized controlled trial. Am J Sports Med 2012:40:2492

43 Ahn JH, Kim JG, Wang JH, et al. Long-Term Results of Anterior Cruciate Ligament Reconstruction Using Bone-Patellar Tendon-Bone: An Analysis of the Factors Affecting the Development of Osteoarthritis. Arthroscopy: The Journal of Arthroscopic \& Related Surgery 2012;28:1114-23.

44 Gerhard P, Bolt R, Dück K, et al. Long-term results of arthroscopically assisted anatomical single-bundle anterior cruciate ligament reconstruction using patellar tendon autograft: are there any predictors for the development of osteoarthritis? Knee Surg Sports Traumatol Arthroscopy 2013;21:957-64.

45 Hoffelner T, Resch $\mathrm{H}$, Moroder $\mathrm{P}$, et al. No increased occurrence of osteoarthritis after anterior cruciate ligament reconstruction after isolated anterior cruciate ligament injury in athletes. Arthroscopy 2012;28:517-25.

46 Inderhaug E, Strand T, Fischer-Bredenbeck C, et al. Long-term results after reconstruction of the $A C L$ with hamstrings autograft and transtibial femoral drilling. Knee Surg Sports Traumatol Arthrosc 2013;21:2004-10.

47 Meuffels DE, Favejee MM, Vissers MM, et al. Ten year follow-up study comparing conservative versus operative treatment of anterior cruciate ligament ruptures. A matched-pair analysis of high level athletes. Br J Sports Med 2009;43:347-51.

48 Murray JR, Lindh AM, Hogan NA, et al. Does anterior cruciate ligament reconstruction lead to degenerative disease?: Thirteen-year results after bonepatellar tendon-bone autograft. Am J Sports Med 2012;40:404-13.

49 Ruffilli A, Buda R, Pagliazzi G, et al. Over-the-Top Anterior Cruciate Ligament Reconstruction Using Single- or Double-Strand Hamstrings Autograft. Orthopedics 2015;38:e635-e643.

50 Streich NA, Reichenbacher S, Barié A, et al. Long-term outcome of anterior cruciate ligament reconstruction with an autologous four-strand semitendinosus tendon autograft. Int Orthop 2013;37:279-84.

51 Struewer J, Frangen TM, Ishaque B, et al. Knee function and prevalence of osteoarthritis after isolated anterior cruciate ligament reconstruction using bonepatellar tendon-bone graft: long-term follow-up. Int Orthop 2012;36:171-7.

52 Struewer J, Ziring E, Frangen TM, et al. Clinical outcome and prevalence of osteoarthritis after isolated anterior cruciate ligament reconstruction using hamstring graft: follow-up after two and ten years. Int Orthop 2013:37:271-7.

53 Sutherland AG, Cooper K, Alexander LA, et al. The long-term functional and radiological outcome after open reconstruction of the anterior cruciate ligament. $J$ Bone Joint Surg Br 2010;92:1096-9.

54 Tengman E, Brax Olofsson L, Nilsson KG, et al. Anterior cruciate ligament injury after more than 20 years: I. Physical activity level and knee function. Scand J Med Sci Sports 2014;24:e491-500.

55 Tiefenboeck TM, Thurmaier E, Tiefenboeck MM, et al. Clinical and functional outcome after anterior cruciate ligament reconstruction using the LARS TM system at a minimum follow-up of 10 years. Knee 2015;22:565-8.

56 Widuchowski W, Widuchowski J, Koczy B, et al. Untreated asymptomatic deep cartilage lesions associated with anterior cruciate ligament injury: results at 10 - and 15-year follow-up. Am J Sports Med 2009;37:688-92.

57 Widuchowski W, Widuchowska M, Koczy B, et al. Femoral press-fit fixation in ACL reconstruction using bone-patellar tendon-bone autograft: results at 15 years follow-up. BMC Musculoskelet Disord 2012;13:115.

58 Ayala-Mejias JD, Garcia-Gonzalez B, Alcocer-Perez-España L, et al. Relationship between Widening and Position of the Tunnels and Clinical Results of Anterior Cruciate Ligament Reconstruction to Knee Osteoarthritis: 30 Patients at a Minimum Follow-Up of 10 Years. J Knee Surg 2017;30:501-8.

59 Cantin 0 , Lustig S, Rongieras F, et al. Outcome of cartilage at 12 years of follow-up after anterior cruciate ligament reconstruction. Orthopaedics \& Traumatology: Surgery \& Research 2016;102:857-61.

60 Ferretti A, Monaco E, Ponzo A, et al. Combined Intra-articular and Extra-articular Reconstruction in Anterior Cruciate Ligament-Deficient Knee: 25 Years Later. Arthroscopy: The Journal of Arthroscopic \& Related Surgery 2016;32:2039-47.

61 Streich NA, Zimmermann D, Bode G, et al. Reconstructive versus non-reconstructive treatment of anterior cruciate ligament insufficiency. A retrospective matched-pair long-term follow-up. Int Orthop 2011;35:607-13.

62 Mihelic $\mathrm{R}$, Jurdana $\mathrm{H}$, Jotanovic $\mathrm{Z}$, et al. Long-term results of anterior cruciate ligament reconstruction: a comparison with non-operative treatment with a followup of 17-20 years. Int Orthop 2011;35:1093-7.
63 Barenius B, Ponzer S, Shalabi A, et al. Increased risk of osteoarthritis after anterior cruciate ligament reconstruction: a 14-year follow-up study of a randomized controlled trial. Am J Sports Med 2014;42:1049-57.

64 Leiter JR, Gourlay R, McRae S, et al. Long-term follow-up of ACL reconstruction with hamstring autograft. Knee Surg Sports Traumatol Arthrosc 2014;22:1061-9.

65 Sajovic M, Stropnik D, Skaza K. Long-term Comparison of Semitendinosus and Gracilis Tendon Versus Patellar Tendon Autografts for Anterior Cruciate Ligament Reconstruction: A 17-Year Follow-up of a Randomized Controlled Trial. Am J Sports Med 2018;46:1800-8

66 Holm I, Oiestad BE, Risberg MA, et al. No difference in knee function or prevalence of osteoarthritis after reconstruction of the anterior cruciate ligament with 4-strand hamstring autograft versus patellar tendon-bone autograft: a randomized study with 10-year follow-up. Am J Sports Med 2010:38:448-54.

67 Risberg MA, Oiestad BE, Gunderson R, et al. Changes in Knee Osteoarthritis, Symptoms, and Function After Anterior Cruciate Ligament Reconstruction. Am J Sports Med 2016;44:1215-24.

68 Grip H, Tengman E, Häger CK. Dynamic knee stability estimated by finite helical axis methods during functional performance approximately twenty years after anterior cruciate ligament injury. J Biomech 2015;48:1906-14

69 Tengman E, Brax Olofsson L, Stensdotter AK, et al. Anterior cruciate ligament injury after more than 20 years. II. Concentric and eccentric knee muscle strength. Scand J Med Sci Sports 2014;24:e501-9.

70 Hui C, Salmon LJ, Kok A, et al. Fifteen-year outcome of endoscopic anterior cruciate ligament reconstruction with patellar tendon autograft for "isolated" anterior cruciate ligament tear. Am J Sports Med 2011;39:89-98.

71 Neuman P, Kostogiannis I, Fridén T, et al. Knee laxity after complete anterior cruciate ligament tear: a prospective study over 15 years. Scand J Med Sci Sports 2012;22:156-63.

72 Marcacci M, Zaffagnini S, Giordano G, et al. Anterior cruciate ligament reconstruction associated with extra-articular tenodesis: A prospective clinical and radiographic evaluation with 10- to 13-year follow-up. Am J Sports Med 2009;37:707-14.

73 Sajovic M, Strahovnik A, Dernovsek MZ, et al. Quality of life and clinical outcome comparison of semitendinosus and gracilis tendon versus patellar tendon autografts for anterior cruciate ligament reconstruction: an 11-year follow-up of a randomized controlled trial. Am J Sports Med 2011:39:2161-9.

74 Lohmander LS, Englund PM, Dahl LL, et al. The long-term consequence of anterior cruciate ligament and meniscus injuries: osteoarthritis. Am J Sports Med 2007;35:1756-69.

75 Cross M, Smith E, Hoy D, et al. The global burden of hip and knee osteoarthritis: estimates from the global burden of disease 2010 study. Ann Rheum Dis 2014;73:1323-30.

76 Arockiaraj J, Korula RJ, Oommen AT, et al. Proprioceptive changes in the contralateral knee joint following anterior cruciate injury. Bone Joint J 2013;95-B:188-91.

77 Hofbauer M, Thorhauer ED, Abebe E, et al. Altered tibiofemoral kinematics in the affected knee and compensatory changes in the contralateral knee after anterior cruciate ligament reconstruction. Am J Sports Med 2014;42:2715-21.

78 Hart JM, Ko JW, Konold T, et al. Sagittal plane knee joint moments following anterior cruciate ligament injury and reconstruction: a systematic review. Clin Biomech 2010;25:277-83

79 Yucesoy B, Charles LE, Baker B, et al. Occupational and genetic risk factors for osteoarthritis: a review. Work 2015;50:261-73.

80 Fernández-Moreno M, Rego I, Carreira-Garcia V, et al. Genetics in osteoarthritis. Curr Genomics 2008:9:542-7.

81 Hart HF, Stefanik JJ, Wyndow N, et al. The prevalence of radiographic and MRIdefined patellofemoral osteoarthritis and structural pathology: a systematic review and meta-analysis. Br J Sports Med 2017;51:1195-208.

82 Culvenor AG, Cook JL, Collins NJ, et al. Is patellofemoral joint osteoarthritis an under-recognised outcome of anterior cruciate ligament reconstruction? A narrative literature review. Br J Sports Med 2013:47:66-70.

83 Frobell RB, Roos HP, Roos EM, et al. Treatment for acute anterior cruciate ligament tear: five year outcome of randomised trial. Br J Sports Med 2015:49:700.

84 Luc B, Gribble PA, Pietrosimone BG. Osteoarthritis prevalence following anterior cruciate ligament reconstruction: a systematic review and numbers-needed-to-treat analysis. J Ath/ Train 2014;49:806-19.

85 Paschos NK. Anterior cruciate ligament reconstruction and knee osteoarthritis. World J Orthop 2017:8:212-7.

86 Xie X, Xiao Z, Li Q, et al. Increased incidence of osteoarthritis of knee joint after $\mathrm{ACL}$ reconstruction with bone-patellar tendon-bone autografts than hamstring autografts: a meta-analysis of 1,443 patients at a minimum of 5 years. Eur $J$ Orthop Surg Traumatol 2015:25:149-59.

87 Poehling-Monaghan KL, Salem H, Ross KE, et al. Long-Term Outcomes in Anterior Cruciate Ligament Reconstruction: A Systematic Review of Patellar Tendon Versus Hamstring Autografts. Orthop J Sports Med 2017;5:232596711770973.

88 Magnussen RA, Carey JL, Spindler KP. Does autograft choice determine intermediateterm outcome of ACL reconstruction? Knee Surg Sports Traumatol Arthrosc 2011;19:462-72

89 Gwilym SE, Pollard TC, Carr AJ. Understanding pain in osteoarthritis. J Bone Joint Surg Br 2008;90:280-7. 
90 Schiphof D, de Klerk BM, Kerkhof HJ, et al. Impact of different descriptions of the Kellgren and Lawrence classification criteria on the diagnosis of knee osteoarthritis. Ann Rheum Dis 2011;70:1422-7.

91 Schiphof D, de Klerk BM, Koes BW, et al. Good reliability, questionable validity of 25 different classification criteria of knee osteoarthritis: a systematic appraisal. J Clin Epidemiol 2008;61:1205-15

92 Hunter DJ, McDougall JJ, Keefe FJ. The symptoms of osteoarthritis and the genesis of pain. Rheum Dis Clin North Am 2008;34:623-43.

93 Bedson J, Croft PR. The discordance between clinical and radiographic knee osteoarthritis: a systematic search and summary of the literature. BMC Musculoskelet Disord 2008:9:116-16.

94 Suter LG, Smith SR, Katz JN, et al. Projecting Lifetime Risk of Symptomatic Knee Osteoarthritis and Total Knee Replacement in Individuals Sustaining a Complete Anterior Cruciate Ligament Tear in Early Adulthood. Arthritis Care Res 2017:69:201-8.

95 Lohmander LS, Ostenberg A, Englund M, et al. High prevalence of knee osteoarthritis, pain, and functional limitations in female soccer players twelve years after anterior cruciate ligament injury. Arthritis Rheum 2004;50:3145-52.

96 Jones LD, Bottomley N, Harris K, et al. The clinical symptom profile of early radiographic knee arthritis: a pain and function comparison with advanced disease. Knee Surg Sports Traumatol Arthrosc 2016;24:161-8
97 Amoako AO, Pujalte GG. Osteoarthritis in young, active, and athletic individuals. Clin Med Insights Arthritis Musculoskelet Disord 2014;7:CMAMD.S14386.

98 Bahr R, McCrory P, LaPrade RF, Meeuwisse W, Engebretsen L, et al. Idrettsskader diagnostikk og behandling: Fagbokforlaget, 2014.

99 Fox AJ, Bedi A, Rodeo SA. The basic science of human knee menisci: structure, composition, and function. Sports Health 2012:4:340-51.

100 Bedi A, Kelly NH, Baad M, et al. Dynamic contact mechanics of the medial meniscus as a function of radial tear, repair, and partial meniscectomy. J Bone Joint Surg Am 2010;92:1398-408

101 Englund M, Guermazi A, Lohmander SL. The role of the meniscus in knee osteoarthritis: a cause or consequence? Radiol Clin North Am 2009:47:703-12.

102 Øiestad BE, Juhl CB, Eitzen I, et al. Knee extensor muscle weakness is a risk factor for development of knee osteoarthritis. A systematic review and meta-analysis. Osteoarthritis Cartilage 2015;23:171-7.

103 Heidari B. Knee osteoarthritis prevalence, risk factors, pathogenesis and features: Part I. Caspian J Intern Med 2011;2:205-12.

104 Bahr R, Holme I. Risk factors for sports injuries--a methodological approach. $\mathrm{Br}$ Sports Med 2003;37:384-92. 